\title{
A case of leprosy in Malawi. Making the final push towards eradication: a clinical and public health perspective
}

\author{
Cieron Roe and Lucy Sarah May
}

\begin{abstract}
Statistically speaking, Malawi has achieved the World Health Organisation's target for the elimination of leprosy ( $<1$ case per 10000 people), yet the disease is still considered a leading cause of long term physical disability. In this case study the authors discuss the presentation of a 39-year-old gentleman to a district hospital in Malawi with multibacillary, lepromatous leprosy. The condition was initially managed in the community as an 'allergy' which suggests that local barriers currently hinder the detection of leprosy in this developing primary care system. Leprosy is a multi-system disease and this gentleman demonstrated evidence of lepromatous orchitis. Promoting an awareness of these systemic manifestations will increase the the detection of complications and circumvent long term morbidity. Efforts to optimise systems of detection, management and public and professional education are essential to drive eradication in these at-risk populations. At an international level, we must strive to fulfil the objectives outlined by the 'Enhanced Global Strategy for Further Reducing the Disease Burden due to Leprosy for 2011-2015'. At a national level, local research should delineate community factors that impede the eradication of leprosy. Developing new diagnostic and epidemiologic tools, more efficacious chemoprophylactic regimens and vaccination for endemic regions would facilitate these efforts.
\end{abstract}

Keywords: Leprosy, Eradication, Africa, World Health Organisation, Malawi, International complication, Communicable disease, Tropical

\section{Multilingual abstracts}

Please see Additional file 1 for translations of the abstract into the six official working languages of the United Nations.

\section{Background}

Leprosy has been endemic in many regions of the world since biblical times. In 2014, 213899 new cases were detected worldwide [1]. Mycobacterium leprae (M. leprae) is transmitted following prolonged close contact with infected patients. The bacilli reside within upper airway secretions and spread through the expulsion and consequent inhalation of airbourne droplets. Although highly contagious, the clinical disease only develops in genetically susceptible individuals. The quality of the immune response determines the outcome of infection. Ridley and

\footnotetext{
*Correspondence: c.roe@doctors.org.uk

Brighton and Sussex Medical School, Brighton, UK
}

Jopling characterised a spectrum based on clinical, histological and immunological variables. They defined three broad syndromes: tuberculoid, borderline and lepromatous leprosy $[2,3]$. The latter develops when $\mathrm{CD} 4^{+} \mathrm{T}$ cells preferentially polarise to a $\mathrm{T}$ helper 2 response. This promotes humoral immunity which fails to clear the intracellular bacilli. Leprosy is characterised by a remarkably long incubation period spanning between six months and twenty years [4]. Lepromatous lesions are characterised by deteriorating sensitivity to heat, pain and tactile sensation as the peripheral nerves denervate. Multiple large plaques develop symmetrically over colder areas of the body. They are hypochromic, erythematous and have indefinite borders. Over time, some of these plaques form nodules, known as lepromas. Borderline cases develop hypochromic spots with slight insensitivity whilst tuberculoid leprosy is characterised by a few isolated erythematous plaques. 


\section{Case presentation}

A 39 year old gentleman initially presented to a community health centre in Malawi's Lilongwe district with widespread skin lesions on the face, torso and the triceps aspect of the right arm. He was referred to the neighbouring district hospital with 'allergies'. The lesions were long-standing and had evolved relatively slowly. He was otherwise well although concerned about patches of anaesthetic skin on his face and on the soles of his feet. He denied any past medical history although his blood pressure was incidentally raised at $150 / 93 \mathrm{mmHg}$. He smoked occasionally and drank moderate amounts of alcohol. On examination the gentleman had widespread skin nodules and scaly plaques with characteristically thick dermis on his cheeks and feet. He had thick facial nodules and there was evidence of eyebrow loss; symptoms consistent with early leonine facies (Fig. 1). This appearance and the description of lesion anaesthesia and peripheral neuropathy were highly suggestive of lepromatous disease. He also had slight discomfort in his right upper quadrant and mild right testicular tenderness and swelling. Due to limited resources, the only suitable laboratory investigations available were a full blood count and urea and electrolytes. The only abnormality was a mildly raised white cell count $\left(12 \times 10^{9} / \mathrm{L}\right)$. The gentleman was assigned a clinical diagnosis of leprosy as defined by the World Health Organisation's (WHO) standard diagnostic criteria in Table 1 [5]. Consequently, he was referred to Kamuzu Central Hospital for treatment with multidrug chemotherapy $(100 \mathrm{mg}$ Dapsone, $50 \mathrm{mg}$ Clofazimine and $600 \mathrm{mg}$ Rifampicin for 12 months).

\section{Case discussion}

\section{Clinical perspective}

In all settings, a detailed travel, social and contact history can accurately predict the risk of exposure. Moet et al. showed that the most important determinants of clinical disease include i) the intensity of contact and ii) inherited susceptibility including HLA-DR2 and nonHLA polymorphism e.g. in TNF- $\alpha$ [6]. Seropositivity represents a 20 -fold increased risk of developing clinical leprosy $[7,8]$ whilst the bacterial load, as measured by a skin smear can predict the transmission risk [6]. Differential diagnoses for multibacillary lepromatous skin lesions include scleroderma, mycosis fungoides, pellagra, asteatosis, ichtyosis and eczema or contact dermatitis. The primary neurological symptoms resemble common mononeuropathies. Where there is systemic involvement, clinicians should consider systemic lupus erythematosus, rheumatoid arthritis, dermatopolymyositis and systemic vasculitis.

Ideally, leprosy should be confirmed by the presence of acid-fast bacilli in skin biopsies or split skin smears. M. Leprae is a gram variable organism and can be decolourised by a Ziehl-Neelsen stain thus a modified Fite stain should be used. Skin biopsies should be taken from the centre of skin plaques or nodules in lepromatous leprosy and the periphery of tuberculoid lesions. Despite being a major referral centre, this district hospital did not have the laboratory facilities to perform split skin smears or skin biopsies. Whilst the WHO standard diagnostic criteria state that these investigations are not required to make a formal diagnosis (Table 1), this situation highlights the inadequacy of laboratory provisions in the Lilongwe health district. To achieve eradication targets, these secondary care institutions require access to reliable, definitive laboratory investigations. Boyce et al. demonstrate that strategies to improve investment at a national and district level are a cost-effective means of increasing detection rates, reducing misdiagnosis and improving the follow up of treatment [9].

This gentleman also complained of a painful and swollen right testicle. The $M$. Leprae bacterium can cause multi-system pathology; approximately $90 \%$ of men with lepromatous leprosy develop orchitis [4]. Table 2 summarises the extent of multi-system involvement. An awareness of these conditions will facilitate early detection and treatment, and prevent the development of long term co-morbidities e.g. infertility.

\section{Public health perspective}

The WHO's 'Strategic Plan for Leprosy Elimination 2000-2005' made a commitment to eliminate leprosy

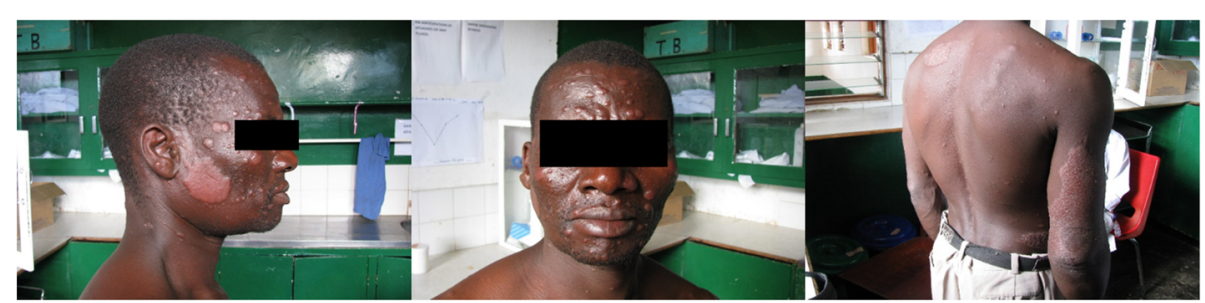

Fig. 1 Presentation of widespread skin lesions consistent with lepromatous leprosy. The patient is beginning to develop leonine facies with a large number of papules and nodules afflicting the face, chest, back, legs and groin. Large well circumscribed plaques were noted on the triceps aspect of the right arm and over his left shoulder and right flank 
Table 1 The WHO diagnostic features for leprosy

World Health Organisation operational diagnostic criteria for leprosy

1. Skin lesion consistent with leprosy and with definite sensory loss, with or without thickened nerves

2. Positive skin smears

In an endemic country or area, an individual should be regarded as having leprosy if he or she shown ONE of the above cardinal signs. Only in rare instances is there a need to use laboratory and other investigations to confirm a diagnosis. Adapted from $\mathrm{WHO}[5]$

through control measures that are accessible at all local health facilities [10]. These control measures emphasised facilities to diagnose and treat patients with multidrug chemotherapy, patient and family counselling, community education, disability support, rehabilitation and referrals for complications. In some nations, the uptake of these strategies was slow and in 2006, the WHO published a revised plan; 'The Global Strategy for Further Reducing the Leprosy Burden and Sustaining Leprosy Control Activities 2006-2010' [11]. This focused on 'morbidity control' to further promote the timely detection of new cases, their treatment with effective multidrug chemotherapy, the prevention of disability and rehabilitation. The strategy emphasised equitable resource distribution and the provision of affordable and easily accessible care. Leprosy has long been a source of stigma thus socio-educational programmes were prioritised to dispel fear and motivate individuals to seek treatment.
Leprosy is a leading communicable cause of neurological disability throughout the globe [12]. As with this gentleman, ensuring timely diagnosis and treatment is the most effective way of mitigating damage to the sensory, motor and autonomic function of peripheral nerves. The WHO definition of Grade 2 disability (G2D) has been proposed as a more robust indicator of international progress than leprosy prevalence because it is less susceptible to operational factors such as treatment duration and case-finding methodology. In 2012 Msyamboza showed that $21 \%$ of patients in their communitybased cross sectional study in Malawi had a G2D [13]. The Enhanced Global Strategy for Further Reducing the Disease Burden due to Leprosy for 2011-2015, set a target to reduce new cases of leprosy with G2D per 100 000 total population by $35 \%$ relative to 2010 . Looking forward, their aim is to reduce the burden to 1 new G2D case per one million population by 2020 [14]. However, a criticism of the indicator is that such a neurological assessment may be too complex for some developing settings, especially for clinicians that haven't received specific training and have no means of monitoring local prevalence [15].

The WHO has defined the elimination of leprosy as a 'national prevalence of less than 1 case per 10000 population' [16]. Malawi fulfils this criteria, however Msyamboza et al. showed that between 2006 and 2011, the prevalence and detection rates actually increased [11]. Furthermore, cure rates for paucibacillary (1-5 lesions)

Table 2 Systems with a significant degree of M. Leprae infiltration and/or dysfunction

\begin{tabular}{|c|c|c|}
\hline System & Complication(s) & Reference(s) \\
\hline Renal system & $\begin{array}{l}\text { Secondary amyloidosis can develop in several organs although it commonly causes kidney } \\
\text { damage by glomerulonephritis (incidence up to } 50 \% \text { ), interstitial nephritis, nephrotic syndrome, } \\
\text { pyelonephritis and acute tubular necrosis. }\end{array}$ & {$[4,18]$} \\
\hline Respiratory system & $\begin{array}{l}\text { M. leprae can infiltrate the upper respiratory tract including the nose, pharynx, larynx, epiglottis } \\
\text { and trachea. Common symptoms include cough, hoarseness, and, occasionally, dyspnoea. } \\
\text { The bronchi and lungs are usually spared. }\end{array}$ & [18-20] \\
\hline Cardiovascular system & $\begin{array}{l}\text { Leprosy (particularly multibacillary) has been associated with arrhythmias, dyspnoea, ventricular } \\
\text { hypertrophy and ST segment abnormalities. M. Leprae can invade the cardiac autonomic system. } \\
\text { Coronary artery disease and arteriographic abnormalities affect approximately } 11 \text { and } 50 \% \text { of } \\
\text { patients respectively. }\end{array}$ & {$[4,18]$} \\
\hline Endocrine system & $\begin{array}{l}\text { Approximately } 90 \% \text { of men develop orchitis, commonly with involvement of the epididymis. } \\
\text { This can lead to infertility, sexual impotence and gynaecomastia. Approximately } 30 \% \text { of patients } \\
\text { develop cortical adrenal lesions. }\end{array}$ & {$[18,20,21]$} \\
\hline Hepato-biliary system & $\begin{array}{l}\text { The incidence of liver involvement is estimated at between } 48 \% \text { and almost } 100 \% \text {. Lepromatous } \\
\text { hepatitis describes portal and centrolobular granulomas, and fibrosis with acid-fast bacilli. Infrequently, } \\
\text { secondary amyloidosis can cause hepatic damage. The gall bladder, biliary system and pancreas are } \\
\text { usually spared. }\end{array}$ & {$[18,22]$} \\
\hline Haematology & $\begin{array}{l}90 \% \text { of lepromatous patients show bacillaemia. Bone marrow infiltration can lead to pancytopaenia. } \\
\text { A widespread lymphadenopathy can also occur. }\end{array}$ & {$[4,18]$} \\
\hline Reproductive system & $\begin{array}{l}\text { Approximately } 90 \% \text { of infected males develop orchitis. Foamy macrophages often form granulomas } \\
\text { which replace the testicular parenchyma. Otherwise, parenchymal fibrosis and hyalinization of the } \\
\text { spermatopoietic tubules may occur. If left untreated this will eventually cause testicular atrophy and } \\
\text { infertility. There is very little involvement of the female genital tract. }\end{array}$ & {$[18,20]$} \\
\hline
\end{tabular}

Systemic involvement is fully reviewed by Klioze et al. [18]. Organ dysfunction correlates with: (i) the degree of infiltration; and (ii) interaction with other factors including amyloid infiltration, infection, leprosy reactions and concomitant drug use [18] 
and multibacillary ( $>5$ lesions) leprosy were 63 and $33 \%$ respectively; substantially below the expected $80 \%$ [13]. This gentleman was misdiagnosed at the community health centre which indicates that despite global initiatives, cases of lepromatous leprosy are still missed in this region of Malawi. Attributable factors may include a lack of decentralisation to health centres for diagnosis and treatment, insufficient knowledge and skills of health centre staff, poor registration and recording systems, and a lack of political commitment by government and health partners [13]. However, to our knowledge there are no recent studies investigating these potential issues in Malawi. In addition to global efforts, individualised, national systems of detection, contact tracing and the provision of affordable treatments are needed to definitively eradicate leprosy in these settings [17].

\section{Conclusions}

In conclusion, beyond the optimal implementation of WHO strategies, global eradication requires the development of national initiatives that detect and treat earlystage disease. There is also a need for novel diagnostic and epidemiologic tools, more efficacious chemoprophylactic regimens and vaccine development. In Malawi, future research should delineate factors influencing the detection and management of lepromatous leprosy in the local community setting. Overall, this case illustrates the need for continued efforts that promote educational programmes for health professionals, sustain control activities in the developing world and promote investment in primary care systems.

\footnotetext{
Learning Points

$>$ Leprosy is still a prevalent communicable disease and a leading cause of long term physical disability even in countries that have statistically achieved the WHO elimination target

$>$ Clinicians must consider leprosy in those with a significant contact history and be aware that leprosy can lead to severe multi-system sequelae

$>$ Wider accessibility to clinical laboratories equipped with the resources to confirm leprosy could improve detection and cure rates, reduce misdiagnosis and unnecessary treatment and enhance patient follow-up.

$\triangleright$ Further research is needed to develop and implement national strategies to address local factors influencing the detection and management of lepromatous disease
}

\section{Additional file}

Additional file 1: Multilingual abstracts in the six official working languages of the United Nations. (PDF $373 \mathrm{~kb}$ )

\section{Acknowledgments}

The authors would like to acknowledge the staff at Nkhoma Hospital for their kind personal and professional support during our time in Malawi.

\section{Authors' contributions}

The gentleman described in this case report was seen by both authors. The corresponding author conceived and produced the initial manuscript. Both authors made valuable contributions throughout and were heavily involved in the production of the final manuscript. Both authors read and approved the final manuscript.

\section{Competing interests}

The authors declare that they have no competing interests.

\section{Ethics approval and consent to participate}

We obtained informed consent from the patient for the specific purpose of using his clinical details and photographs for the publication of a case study in a research journal and for educating health professionals. Confidential personal details have been removed and the photographs have been modified to ensure full anonymity.

Received: 7 August 2015 Accepted: 20 July 2016

Published online: 02 September 2016

\section{References}

1. Global leprosy update, 2013. reducing disease burden. Wkly Epidemiol Rec. 2015;90(36):461-76.

2. Ridley DS, Jopling WH. Classification of leprosy according to immunity. A five-group system. Int J Lepr Other Mycobact Dis. 1966;34(3):255-73.

3. Ridley DS, Jopling WH. A classification of leprosy for research purposes. Lepr Rev. 1962;33:119-28.

4. Lastoria JC, Abreu MA. Leprosy: review of the epidemiological, clinical, and etiopathogenic aspects - part 1. An Bras Dermatol. 2014;89(2):205-18.

5. WHO. Diagnosis of leprosy. 2015; http://www.who.int/lep/diagnosis/en/. Accessed 10 June 2015.

6. Moet FJ, Meima A, Oskam L, Richardus JH. Risk factors for the development of clinical leprosy among contacts, and their relevance for targeted interventions. Lepr Rev. 2004;75(4):310-26.

7. Ulrich M, Smith PG, Sampson C, et al. IgM antibodies to native phenolic glycolipid-I in contacts of leprosy patients in Venezuela: epidemiological observations and a prospective study of the risk of leprosy. Int J Lepr Other Mycobact Dis. 1991;59(3):405-15.

8. Douglas JT, Celona RV, Abalos RM, Madarang MG, Fajardo T. Serological reactivity and early detection of leprosy among contacts of lepromatous patients in Cebu, the Philippines. Int J Lepr Other Mycobact Dis. 1987;55(4): 718-21.

9. Boyce SP, Berruti Andrés A, Connolly H, Schneidman M. Evaluating the Economic and Health Impacts of Investing in Laboratories in East Africa: Development and Application of a Conceptual Framework. Washington: Health, Nutrition and Population (HNP) Discussion Paper Series; 2015.

10. WHO. The final push towards elimination of leprosy: strategic plan 2000-2005. Geneva: WHO; 2000.

11. WHO. Global strategy for further reducing the leprosy burden and sustaining leprosy control activities 2006-2010. Geneva: WHO; 2006

12. Lockwood DN. Leprosy elimination-a virtual phenomenon or a reality? BMJ. 2002;324(7352):1516-8.

13. Msyamboza KP, Mawaya LR, Kubwalo HW, et al. Burden of leprosy in Malawi: community camp-based cross-sectional study. BMC Int Health Human Rights. 2012;12:12-2. 08/0602/26/received07/31/accepted.

14. WHO. Enhanced Global Strategy for Further Reducing the Disease Burden due to Leprosy for 2011-2015. New Delhi: WHO; 2009.

15. Neurology in sub-Saharan Africa-WHO cares? Lancet Neurol. 2006;5(8):637

16. WHO. Leprosy elimination. 2015; http://www.who.int/lep/en/. Accessed 10 June 2015.

17. Smith CS, Noordeen SK, Richardus JH, et al. A strategy to halt leprosy transmission. Lancet Infect Dis. 2014;14(2):96-8.

18. Klioze AM, Ramos-Caro FA. Visceral leprosy. Int J Dermatol. 2000;39(9): 641-58.

19. de Abreu MA, Michalany NS, Weckx LL, Neto Pimentel DR, Hirata CH, de Avelar Alchorne MM. The oral mucosa in leprosy: a clinical and histopathological study. Braz J Otorhinolaryngol. 2006;72(3):312-6. 
20. Liu TC, Qiu JS. Pathological findings on peripheral nerves, lymph nodes, and visceral organs of leprosy. Int J Lepr Other Mycobact Dis. 1984; 52(3):377-83.

21. Desikan KV, Job CK. A review of postmortem findings in 37 cases of leprosy. Int J Lepr Other Mycobact Dis. 1968;36(1):32-44.

22. Agarwal SC, Maheshwari HB, Mittal MM, Kumar S. A histological study of liver lesions in leprosy. Indian J Med Res. 1973;61(3):389-95.

Submit your next manuscript to BioMed Central and we will help you at every step:

- We accept pre-submission inquiries

- Our selector tool helps you to find the most relevant journal

- We provide round the clock customer support

- Convenient online submission

- Thorough peer review

- Inclusion in PubMed and all major indexing services

- Maximum visibility for your research

Submit your manuscript at www.biomedcentral.com/submit 